\title{
Transdermal Delivery Systems for Biomolecules
}

\author{
Ma. Concepción Peña-Juárez ${ }^{1}$ (D) O Omar Rodrigo Guadarrama-Escobar ${ }^{2}$ (D) · José Juan Escobar-Chávez ${ }^{1}$ (D)
}

Accepted: 29 November 2020 / Published online: 6 January 2021

(C) The Author(s), under exclusive licence to Springer Science+Business Media, LLC part of Springer Nature 2021

\begin{abstract}
Purpose The present review article focuses on highlighting the main technologies used as tools that improve the delivery of transdermal biomolecules, addressing them from the point of view of research in the development of transdermal systems that use physical and chemical permeation enhancers and nanocarrier systems or a combination of them.

Results Transdermal drug delivery systems have increased in importance since the late 1970s when their use was approved by the Food and Drug Administration (FDA). They appeared to be an alternative resource for the administration of many potent drugs. The first transdermal drug delivery system used for biomolecules was for the treatment of hormonal disorders. Biomolecules have been used primarily in many treatments for cancer and diabetes, vaccines, hormonal disorders, and contraception.

Conclusions The latest technologies that have used such transdermal biomolecule transporters include electrical methods (physical penetration enhancers), some chemical penetration enhancers and nanocarriers. All of them allow the maintenance of the physical and chemical properties of the main proteins and peptides through these clinical treatments, allowing their efficient storage, transport, and release and ensuring the achievement of their target and better results in the treatment of many diseases.
\end{abstract}

Keywords Transdermal drug delivery $\cdot$ Transdermal systems $\cdot$ Chemical and physical enhancers $\cdot$ Biomolecules $\cdot$ Proteins $\cdot$ Microneedles

\section{Introduction}

Drug delivery is related to many problems focused on the molecular stability, pharmacokinetic, and amphoteric nature of a substance. Due to chemical instability and high degradation by enzymatic action regardless of the distance to the specific target organ, all of this is more complicated when the bioactive substance that is intended to be administered is a biomolecule, such as peptides and proteins [1].

Currently, there is a system that is applied to the proteindrug delivery, which is a non-conventional system developed

José Juan Escobar-Chávez

josejuanescobar@comunidad.unam.mx

1 Facultad de Estudios Superiores Cuautitlán-Universidad Nacional Autónoma de México, Unidad de Investigación Multidisciplinaria, Carretera Cuautitlán-Teoloyucan, km 2.5 San Sebastián Xhala, C.P. 54714 Cuautitlán Izcalli, México, Estado de México, Mexico

2 Sección de Estudios de Posgrado e Investigación de la Escuela Nacional de Ciencias Biológicas. Programa de Posgrado: Doctorado en Ciencias Químico Biológicas-Instituto Politécnico Nacional, Prolongación de Carpio y Plan de Ayala s/n. Col. Santo Tomás C. P. 11340, Alcaldía Miguel Hidalgo, Ciudad de México, Mexico primarily for protein and peptide drug delivery. This new delivery system has a higher efficiency that improves the passage of the protein drug to the skin [2]. The transdermal drug delivery (TDD) system reduces potential exposure to side effects in the host and improves protein stability by also reducing enzymatic degradation, which is very common to occur when a drug takes the most conventional routes to enter the body, such as oral and subcutaneous routes. Mainly, TDD systems avoid the first pass of metabolism, which occurs in the liver [3]. The protein and peptide drugs are important in many innovative treatments, such as immunotherapy, where biomolecules, such as antibodies, growth factors, and interleukins, are used. These are proteins with high susceptibility to degradation to many endogenous and exogenous factors, such as temperature and $\mathrm{pH}$, and most importantly, enzymatic degradation and immune clearance.

One of the most important advantages of the transdermal route is to maintain drug release in a constant and prolonged release to achieve optimal blood circulation concentrations [4]. For transdermal protein-drug delivery systems, specific methods or devices are used to allow or enhance intact passage through the stratum corneum (SC). The most suitable systems for the release of biomolecules are the third- 
generation transdermal delivery systems, whose effects are directed to the SC. For TDD systems of biomolecules and vaccines, thermal ablation and microneedles are the most widely used physical penetration enhancers. However, there are many other systems that have been tested for transdermal release of biomolecules [3] that have been included in the second and third generation of transdermal delivery systems, such as iontophoresis and electroporation.

This article highlights the main technologies used as tools that improve transdermal protein-drug delivery systems, addressing them from the point of view of research in the development of transdermal systems where many technologies and devices have a high possibility of use in conventional drug treatments, such as nanotechnology devices. The authors provide an overview of the various systems that exist in TDD that have been tested and proposed for the transdermal delivery of biomolecules.

\section{Skin Anatomy}

The skin is a three-layer laminate that is made up of the SC, the epidermis, and the dermis [5]. The epidermis is the outermost layer and is formed from the stratified epithelium (the stratum germinativum, spinosum, granulosum, lucidum, and corneum) (Fig. 1).

Fig. 1 Cross-sectional scheme of the skin. The main epidermis stratum classification is observed such as the dermis and hypodermis components
The SC is the outermost and impermeable skin layer that prevents the entry of most chemicals [6]. This barrier is formed by around 10 to 25 lines of dead keratinocytes (corneocytes) that have united with each other with corneodesmosomes forming a wall embedded in a lipidic matrix. The extracellular matrix is formed by lipids, such as fatty acids, ceramides, cholesterol, cholesterol sulfate, and sterol/ wax esters arranged in lamellae, and multiple lipid bilayers, although the matrix is primarily composed of ceramides [7, 8]. Corneocytes contain involucrin, loricrin, and cornifin around their periphery and have a thickness of $10 \mu \mathrm{m}$, but this can be modified by factors such as hydration and the anatomic site of the skin [9]. This stratum contains high amounts of keratin inside the corneocytes, and the keratin filaments provide the hexagonal shape and stratum mechanical strength of the corneocyte [10]. In addition, the SC acts as a barrier, preventing desiccation and pathogen entry and protecting against ultraviolet rays. The SC also plays an important role in wound repair.

\section{Transdermal Delivery Route}

The transdermal delivery route has been used many times for the local application of therapeutic substances, and it is a

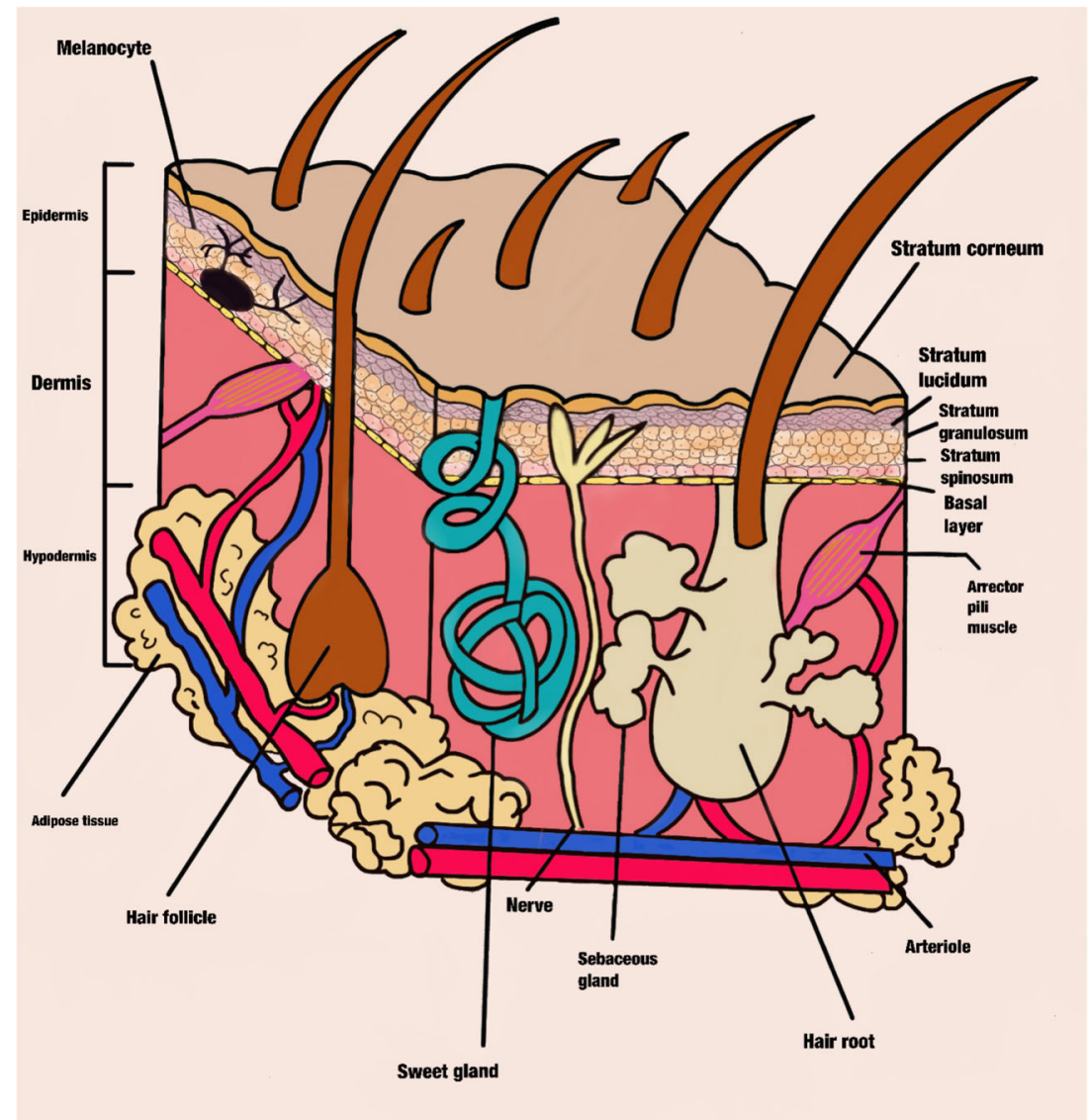


practice that is still used and that will continue to grow in the coming years.

The transdermal drug delivery systems also allow homogeneous absorption and have good pharmaceutical efficiency, reducing the adverse effects that drugs could cause in the host and reduce the drug risk to suffer alterations caused by enzymatic factors and the immune system present in the intrinsic environment. Besides that, these systems are more comfortable for the patient [11].

This method is formed by steps that start when the therapeutic molecule enters the skin until it enters the blood circulation. The first step is penetration, which occurs when the drug is deposited onto the specific skin layer. Later, the permeation step occurs when the molecule diffuses from one layer to another. Finally, in the resorption process, the drug enters the bloodstream $[8,12]$.

This type of drug delivery system has advantages over traditional systems because it can allow the storage of small amounts of drugs in the transport and delivery structure, which are developed by nanotechnology using mainly polymeric nanomaterials made with biopolymers, microneedles, and nanoparticles.

With these devices, it is possible to improve drug delivery and its bioavailability. Thus, it is possible to reduce the frequency between drug administrations. The most innovative property is that the device is only replaced when the dose is finished and it can take several days [13, 14]. The exact side effects that they could trigger are unknown, since they could mainly depend on the type of bioactive drug it contains, which could be related to some effects of the mechanical properties of the skin [15] (Table 1).

\section{Biomolecule Medical Application: Possible Target for Transdermal Protein Delivery Systems}

Peptides and proteins have long been important resources in the treatment of many diseases. Many of the therapies that are applied for many diseases have recently used peptides and proteins, which is called biological therapy and focuses on the production of the main proteins obtained from living organisms such as transforming bacteria.

The main diseases which are treated with proteins are diabetes, hemophilia, infectious diseases, and anemia. These therapeutic proteins are primarily hormones, interleukins, anticoagulants, and enzymes, which are recombinant proteins. Other protein drugs, such as calcitonin, rituximab, gemtuzumab, insulin, epidermal growth factor, and interferons, are best known for their importance in the treatment of osteoporosis, lymphoma, leukemia, and diabetes mellitus [16].

The most employed biological protein therapy is immunotherapy, which has several applications. One of the most important applications is cancer treatment, which is a specific treatment that employs cytokines, a kind of protein produced by the immunity system that helps the patient's immune system eliminate cancer cells and prevents the replication of cancer cells. These immune proteins are classified in therapeutic groups known as cytokines, monoclonal antibodies, tyrosine kinase inhibitor, and rapamycin receptor inhibitors in mammals (mTOR) [17]. Two main kinds of cytokines are the most importantly used in biological therapies: interleukins and interferons. Production is carried out with laboratory animals and once extracted and purified, they are used by injection into a human recipient for clinical treatment (e.g., monoclonal antibodies). However, there are many applications for products, such as antibodies obtained from live organisms and these are used mainly for the prevention of diseases such as in the development of vaccines. The most important pharmaceutical products are listed in Table 2 [3].

Each one of these peptides or proteins has a different method of administration, such as intravenous, oral, topical, or intravesical. Some other proposed methods of administration that would avoid the difficulties of the route of administration and offer comfort to the user include the nasal, pulmonary, ocular, and rectal routes [18], which could be as invasive as the traditional routes in many cases. The main drawback of

Table 1 Advantages and disadvantages of transdermal drug delivery systems

Advantages Disadvantages

High storage of drug-protein system

Short action time

Improve the bioavailability

Reduce the administration frequency

Reduce the adverse effects caused by the drug intake

Availability constant and uniform plasma levels

Easy replacement when content is out of stock

Apparently without secondary effects

These are minimally invasive techniques

These techniques do not affect pharmacological activity of the drug protein

These techniques do not modify protein drug effectiveness
Likelihood of skin irritation derived from the device compounds Likelihood of skin irritation derived from the drug protein Inflammation and irritation in the area of action Passage of pathogenic microorganisms and skin microbiota 
this type of therapies is that traditional administration such as subcutaneous injection and intravenous administration can modify their effectiveness, since the route of administration may vary in different clinical circumstances; for example, it may contribute to an increase in blood pressure [19].

When any substance, including proteins, enters the bloodstream regardless of the route of administration, these proteins are exposed to many environmental threats such as sequestration by the reticuloendothelial system mainly for macrophage internalization, enzymatic degradation and absorption and elimination of serum proteins by the liver [20-24], which is an important factor to consider, since it represents a low efficiency in the application of biological therapy due to its high rate of degradation and elimination [25]. In addition to protecting the lability of all therapeutic proteins, it is also about preventing them from exerting their activity in places that do not require it. Although immunotherapy is more effective and less toxic than therapies made with chemical molecules, these immune proteins also trigger adverse effects in the host, such as autoimmunities and non-specific inflammatory processes [26]. For these reasons, research is being carried out on the use of alternative technologies with which these side effects can be controlled, such as with the use of nanotechnology using polymers, with which these proteins can be protected, favoring their transport and direct delivery to their objective, preventing them from exerting their toxic effect on non-specific cells and sites [27].

Nanocarriers, such as nanotubes, [28] microneedles (MNs) [29-31], fusion peptide carriers [32], or peptide-conjugated nanoparticles (NPs) $[33,34]$ are some of the main carriers and protective systems used in immunotherapy, regardless of the size or structure of the molecule to be transported and protected, which could be genetic material, interferon, interleukins, or antibodies.

In 1979, the US FDA approved the use of TDD systems and their use has been increasing in relevance for protein drugs because for some molecules these delivery systems improve the solubility of the compound, in addition to allowing it to pass efficiently through the skin.

There are important findings in research revealing that TDD technologies allow the loading, transport, and release of protein drugs. They are very promising for the effective treatment of local cancers, with skin location, and they have a second benefit of activating the immune system from a remote distance. Some of them have been developed to carry ribonucleic acid (RNA) that can regulate localized gene expression within a known target. In other cases, it is possible to use an immunologic protein that could produce a strong adaptive immune response against a specific antigen in the case of vaccines, where it could be made with the tumor antigen expressed in the gene, tumor-related protein or peptide, specific epitope, or cell lysate [35].

For immunotherapy, it might be possible to employ monoclonal antibody-loaded TDD systems and tumor agnostic therapies, non-specific immunotherapies (use of interferons and interleukins), and cancer theranostic treatment where SC could be interrupted by a nanogel delivering a drug through the skin and allowing it to accumulate at the tumor site [36] or these systems may even function by delivering vaccine antigens (cancer vaccines) using nanoparticles and liposomes as antigenic carriers loaded on nanogels to pass the antigen through the SC by iontophoresis [37]. It is also possible to use microneedles loaded with Dermatophagoides farinae extract to achieve effective allergen release and effective immune response induction [38].

These strategies have a wide range of application in various skin pathological circumstances, in addition to their main role in cancer therapy, and many products are used for the treatment of cancer. Some of the commercial pharmaceutical products used for cancer therapy, which are administered transdermally, are described in Table 3 [39].

Table 2 Most relevant molecules where the TDD is applied for its administration

\begin{tabular}{lll}
\hline Protein, hormones, peptides & Use in the treatment of & Produced by \\
\hline Estradiol/levonorgestrel & Menopausal symptoms & Climara Pro Bayer Healthcare Pharmaceuticals (Wayne, NJ) \\
Estradiol & Menopausal symptoms & Estraderm Novartis (East Hannover, NJ) \\
Ethinyl estradiol/norelgestromin & Contraception & Ortho Evra Ortho-McNeil Pharmaceutical (Raritan, NJ) \\
Fertility hormone & Female infertility & Vyteris/Ferring \\
Heat-labile enterotoxin of E. coli & Travelers' diarrhea & Iomai \\
Human growth hormone & Growth hormone deficiency & TransPharma/Teva \\
Influenza vaccine & Influenza prophylaxis & Becton Dickinson/Sanofi-Pasteur \\
Insulin & Diabetes mellitus & Zealand Pharma/Altea \\
Parathyroid hormone (1-34) & Osteoporosis & Zosano Pharma, Inc. \\
Testosterone & Female sexual dysfunction & Acrux/VIVUS \\
Testosterone disorder & Hypoactive sexual desire disorder & Procter \& Gamble/Watson \\
Testosterone & Testosterone deficiency & Testoderm Alza, Mountain View, CA \\
\hline
\end{tabular}


Through the use of transdermal delivery systems, it is sought to increase the solubility and stability, the circulating life, and the pharmacokinetic properties of drug proteins and peptides. It is recommended to consider that the TDD system is not applicable to many of the biomolecules that are used as medical treatments since the success in the transdermal passage could depend on certain factors. The efficacy of this therapeutic system depends both on the physical and chemical properties of the proteins and on the percutaneous administration systems of biomolecules to be used. Regarding protein, the main physical properties to consider are the shape and size, molecular weight, solubility, and amphoteric nature, the latter being perhaps one of the most important to consider since due to its amphoteric property it can migrate in an electric field and its migration direction depends on the net charge that it has. The knowledge of this property could help to elucidate which are the best percutaneous administration systems to facilitate passage through the SC. In the case of charged proteins, physical (electrical) enhancers are the best option to use. The chemical nature of proteins is another especially important factor to know. This composition could help us to choose the best TDD system through which the protein will pass through the SC avoiding the reactivity of some functional groups of proteins. For these reasons, there is little increase in the development of new therapeutic formulations administered by TDD systems, since there are some protein properties that need to be studied and analyzed to know if they can be administered by this route without affecting its stability and pharmacokinetic properties.

\section{Passage of Biomolecules through the Skin}

Peptides are molecules that have a molecular weight between $300 \mathrm{Da}$ and $1000 \mathrm{kDa}$. This molecular weight depends on the molecular structures and their lengths with a small amount of amino acids or constitutes a protein with a complex structure. These molecules are charged in a physiological $\mathrm{pH}$ and are hydrophilic, which complicates their permeability across the skin. Some drugs have a lower or higher affinity with the lipophilic condition of the SC, which determines the quantity of the molecule that can cross this layer of the skin naturally. Therefore, it is better to use a technique that improves passage to the skin, using or not natural permeation molecular routes avoiding the degradation of peptides or proteins and ensuring passage and integrity during the transport and release processes [40].

There are important skin conditions that can change permeability, such as age, heat, racial differences, freezing, abrasion, chemical irritant activity, and some diseases such as atopic dermatitis and psoriasis. It is very important to recognize these for the development and use of devices employed in transdermal protein-drug delivery.

In the skin, three molecular permeation routes are the most important: intracellular, intercellular, and follicular routes. All of these are beneficiated by the concentration gradient of the molecules present in the milieu, allowing passive diffusion across the SC [41]. Moreover, physicochemical properties from the molecule affect its passage through the SC. Hydrophobic molecules can cross the SC intercellularly, whereas hydrophilic molecules cross intracellularly by corneocytes. Passage through the skin can take place through so-called cutaneous defects, in which the skin has a discontinuity, such as sweat glands or hair shafts [42].

In the skin, the SC and lipid layers have a barrier function, as both prevent the loss of water and avoid the entry of any substances, molecules, or microorganisms from the environment or microbiome. These layers play a crucial role in the passive passage of proteins and other chemicals into the skin. The liquid flux between the lipid layer depends on the lamellar and linear lipid matrix arrangement. The lamellar layer is generally oriented parallel to the $\mathrm{SC}$, and linear lipids are perpendicular to the SC. If no long-periodicity phase (LPP) exists, the permeability increases [43]. However, if the orthorhombic phase (OP) predominates, the permeability of the lipids is reduced, and if the OP predominates in the lateral layer, the permeation decreases [44]. The LPP is primarily formed by ceramides, cholesterol, and free fatty acids, and these have a unique tri-layer organization, while an all-trans chain lipid organization exists in the OP phase, which has a rectangular crystalline lattice and no mobility.

Table 3 Some of the main products employed for cancer therapy by using TDD systems

\begin{tabular}{ll}
\hline Carrier & Drug \\
\hline Dextran nanoparticle/HA MNs & aPD1 \\
HA nanoparticle/HA MNs & aPD1/1-Methyl-DL-tryptophan \\
OSM-(PEG-PAEU) and poly(I:C) layer-by-layer coated MN & Ovalbumin plasmid/poly(I:C) \\
PEI modified single-wall carbon nanotubes & siRNA targeting \\
Polyelectrolyte multilayers coated MNs & p53 DNA \\
SPACE-EGF fusion peptide & siRNA silencing c-Myc \\
Tat and PEI modified gold nanoparticles & DNA plasmid encoding microRNA-221 inhibitor gene \\
\hline
\end{tabular}




\section{Biomolecule Percutaneous Administration Systems}

A challenge in transdermal delivery systems is the large molecular weight from some biomolecular drugs due to problems crossing the SC. Many technologies allow the passage of drugs through the skin; however, these molecules can be exposed to degradation by environmental modifications, such as temperature, humidity, oxygen, carbon dioxide, light (determined by their chemical integrity), and diminished therapeutic effects, which can even lead to the decomposition of the molecule or the generation of toxic products. The degradation mechanisms that are present in organic molecules are the same in organic compounds; however, these reactions are in low concentrations.

Prausnitz and Langer in 2008 described third-generation delivery systems including thermal ablation, electroporation, cavitational ultrasound, and combinations of chemical enhancers, biochemical enhancers, microdermabrasion, and MNs [45]. These can improve the passage of peptides and proteins through the skin because they can allow therapies that use vaccines, peptides, macromolecules, and hydrophilic molecules. These transdermal delivery systems are suitable for proteins for the reason that they do not interfere with the protein structure and do not affect its stability and properties. All these protein delivery mechanisms are employed for drug delivery; however, some are not accepted by the patient because, in very particular cases, especially those that use electric current, they can produce inflammation and irritation in the area of action, which is bothersome for patients. In this article, we classified the main biomolecule cutaneous administration systems in active and passive methods, within the active ones we have mainly electroporation, iontophoresis, and ultrasound, and in the passive methods we have the use of chemical penetration enhancers.

\section{Active Methods: Electrical Delivery}

Transdermal drug delivery has been used for many years, and the skin was thought to be impervious to exogenous chemical molecules. Currently, it is known that the skin is a semipermeable barrier, which allows its use as a transport route for molecules, allowing the molecule to reach the therapeutic target intact. However, due to its anatomy, hydrophilic molecules can only pass through the skin if they are small, and even then, in many cases, they require help from an electric field (electrotherapies), as in the case of electroporation [46] and iontophoresis [47]. These techniques use a low-voltage supplementation (direct current) around the drug site, allowing and enhancing passage through the skin [48]. When an electric field is applied to the skin, a large molecular movement occurs and the molecule can take the path of the hair follicle through the skin or induce pore formation $[49,50]$.
There is another technology using acoustic transmission (sonophoresis) that is used in medical trials, such as hyperthermia treatment, physical therapy, and ultrasonic surgery, which has the ability to facilitate drug transport to the skin [51]. Through this technique, mechanical waves of medium or low frequency are transferred to a physical medium, such as a specific gel, which allows it to propagate and transmit energy. In the ultrasonic system, wave sounds have an oscillation frequency greater than $20 \mathrm{kHz}$ [52].

The TDD systems are an alternative route that allows the control of the drug release and decreases the possibility of any side effects associated with levels that are higher than the minimum pharmacological concentration, reducing pharmacological dosing times because a patch is administered every 24 to $72 \mathrm{~h}$. This eliminates the risk of metabolism of the therapeutic agent and the loss of the available dose. In addition, there are other advantages, such as the noninvasive drug delivery method, which can be discontinued at any time [53]. To facilitate TDD to improve SC permeation, some technologies improve drug flux of difficult drugs [54], such as cryioneumatic and photpneumatic technologies, sonphoresis, iontophoresis, electroporation, jet injection, and $\mathrm{MN}$, which are used in the delivery of many drugs [55].

The disadvantage in the above cases is that all devices require a low-voltage supplement. In addition, it is necessary to purchase equipment to manage the electrical current. In addition, in some people it can cause sensitivity, such as tingling and irritation, and the technique can even cause blistering of the skin. In these cases, when the technique is not well applied, it can cause burns to the skin. In all circumstances, these techniques must be applied by trained personnel.

Despite these drawbacks, considerable research has been focused on the transport of peptides through the skin with good results. In Table 4, we list some examples of these studies, the biomolecules and penetration enhancers, and the main result of each. The table also indicates whether the physical penetration enhancer acts alone or is enhanced by a combination with another enhancer or nanocarrier [12, 56-66].

\section{Chemical Penetration Enhancers}

Many compounds have been employed to improve the penetration of substances across the skin, such as azone, pyrrolidones, alkanols, sulfoxides, glycols, alcohols, and surfactants [67]. Each of the chemical penetration enhancers has a specific action mechanism in the skin penetration process.

Due to the characteristics of the upper layer of the skin, which is specialized in avoiding and preventing the entry of any molecule or pathogen, the SC is complicated in terms of the passage of molecules greater than $500 \mathrm{Da}$, but it is not impossible. In many cases, this process can be carried out using penetration enhancer molecules, which have good results in terms of penetration of molecules through the skin. 
However, it represents a disadvantage because it could permit not only pathogens but also microorganisms in the cutaneous microbiota to enter as a consequence of cellular disruption integrity and the focal detachment of superficial corneocytes, such as in the use of thioglycolate in depilatory treatments [67]. The process of percutaneous absorption of a therapeutic molecule consists of several processes, which include the dissolution and release of the therapeutic agent, partition and diffusion within the SC, partition from the SC to the aqueous phase of the epidermis and its diffusion, and finally, access to the systemic circulation and target tissue.

There are three routes through which any molecule can breach this and reach the microcirculation through the tissue. These are the intercellular, transcellular, and transappendageal routes, but the route can depend on the drug's molecular weight (Fig. 2) [68].

Chemical penetration enhancers are a good alternative to allow the passage of biomolecules, but most of them cause skin irritation, which is uncomfortable for patients [12]. In many cases, the penetration enhancers have synergic activity when they are used in combination, [69] but they can generate more skin irritation problems. The mode of action of these enhancers is different for each one and depends on the mechanism by which it interacts with the compounds of the SC. Due to this capacity, it has been classified according to their interaction ability in those that (a) interact with lipid heads within aqueous domains of the lipid bilayers and interact with the lipid alkyl chain, (b)

Table 4 Some examples about the use of chemical and physical penetration enhancers for the passage of biomolecules through the skin

\begin{tabular}{|c|c|c|c|c|}
\hline Biomolecule & Percutaneous method & Model & Results & Author \\
\hline $\begin{array}{l}\text {-Plasmid (pRFP) } \\
\text {-Cotransfection RFP and green } \\
\text { fluorescent protein (pGFP) }\end{array}$ & Nanoelectroporation & $\begin{array}{l}\text { CHO and HEK } 293 \\
\text { cells }\end{array}$ & $\begin{array}{l}\text {-Positive protein transfection in the } 81 \% \text { of } \\
\text { CHO cells } \\
\text {-Cell viability of } 98 \% \text {. } \\
\text {-Transfection in HEK } 293 \text { with efficiency of } \\
67 \%\end{array}$ & $\begin{array}{r}\text { Xi Xie et al., } \\
2013 \text { [55] }\end{array}$ \\
\hline -CRISPR/Cas9 gene editing & Tube electroporation & $\begin{array}{l}\text { Rabbit fibroblast cell } \\
\text { culture }\end{array}$ & $\begin{array}{l}\text {-Effective release of CRISPR/Cas9 RNP and } \\
\text { ssODNs and precise gene editing in rabbit } \\
\text { and human cells }\end{array}$ & $\begin{array}{l}\text { Linyuan Ma, } \\
\text { et al., } \\
2019 \text { [56] }\end{array}$ \\
\hline -DNA plasmid/Alexa Fluor 594 & Electroporation & $\begin{array}{l}\text { Hippocampal slice } \\
\text { cultures }\end{array}$ & -Protocol & $\begin{array}{l}\text { Wiegert J. S. } \\
\text { et al., } \\
2017 \text { [57] }\end{array}$ \\
\hline $\begin{array}{l}\text {-mRNA encoding the SARS-CoV-2 N } \\
\text {-Wild-type icSARS-CoV-2 } \\
\text { (icSARS-CoV-2-WT) }\end{array}$ & Electroporation & VeroE6 cells & $\begin{array}{l}\text {-Infected cells developed cytopathic effects } \\
4 \text { days after transfection, producing } \\
\text { infectious virus } \\
\text {-Developed a similar replication kinetics on } \\
\text { Vero E6 cells }\end{array}$ & $\begin{array}{l}\text { Xie X. et al., } \\
2020[58]\end{array}$ \\
\hline $\begin{array}{l}\text {-Transdermal delivery of bovine serum } \\
\text { albumin (BSA), } 66 \mathrm{kDa} \text { protein } \\
\text {-Alexa Fluor } 555 \text { BSA conjugate }\end{array}$ & $\begin{array}{l}\text { Iontophoresis } \\
\text { Microporation with } \\
\text { maltose } \\
\text { microneedles }\end{array}$ & $\begin{array}{l}\text { Hairless rat skin } \\
\quad \text { (in vivo and in vitro) }\end{array}$ & $\begin{array}{l}\text {-Significant increase of penetration into the } \\
\text { skin as compared only with } \mathrm{MN}\end{array}$ & $\begin{array}{l}\text { Bai Y. et al., } \\
\text { 2014 } \\
{[59]}\end{array}$ \\
\hline $\begin{array}{l}\text {-Interleukin-2 (IL-2) in treatment of } \\
\text { malignant pleural effusion }\end{array}$ & Sonophoresis & $\begin{array}{l}\text { Volunteers in treatment } \\
\text { of malignant pleural } \\
\text { effusion }\end{array}$ & $\begin{array}{l}\text {-The therapy could improve the delivery of } \\
\text { IL-2 employing Chinese medicine }\end{array}$ & $\begin{array}{l}\text { Tian A. } \\
\text { et al., } \\
2019 \\
{[60]}\end{array}$ \\
\hline -CHK-R4 heptapeptide & $\begin{array}{l}\text { Chemical Penetration } \\
\text { enhancer }\end{array}$ & $\begin{array}{l}\text { Hs68 human dermal } \\
\text { fibroblasts }\end{array}$ & -Accelerated cellular penetration & $\begin{array}{l}\text { Hur G. et al., } \\
2019 \\
{[61]}\end{array}$ \\
\hline $\begin{array}{l}\text {-Composite microneedles integrated } \\
\text { with insulin-loaded } \mathrm{CaCO}_{3} \text { micro- } \\
\text { particles and PVP }\end{array}$ & $\begin{array}{l}\text { Microneedles and } \\
\text { microparticles }\end{array}$ & Diabetic rats & $\begin{array}{l}\text {-High efficiency } \\
\text {-Constant delivery }\end{array}$ & $\begin{array}{l}\text { Liu D. et al., } \\
2018[62]\end{array}$ \\
\hline $\begin{array}{l}\text {-Development of vector for skin cancer } \\
\text { (cell-penetrating peptide) }\end{array}$ & $\begin{array}{l}\text { Methyl- } \beta \text {-cyclodextrin } \\
(\mathrm{M} \beta \mathrm{CD}) \text { nanoparti- } \\
\text { cles }\end{array}$ & A431 cells & $\begin{array}{l}\text {-Inhibited the internalization of peptide into } \\
\text { the cells }\end{array}$ & $\begin{array}{l}\text { Gan B.K. } \\
\text { et al., } \\
2018[63]\end{array}$ \\
\hline -Transdermal delivery of ketoprofeno & $\begin{array}{l}\text { Peptide dendrimers and } \\
\text { sonophoresis }\end{array}$ & $\begin{array}{l}\text { Swiss albino mouse } \\
\text { skin }\end{array}$ & $\begin{array}{l}\text {-Synthesized peptide dendrimers could } \\
\text { increase the transdermal permeation of } \\
\text { ketprofen }\end{array}$ & $\begin{array}{l}\text { Manikkath J. } \\
\text { et al., } \\
2017 \text { [64] }\end{array}$ \\
\hline -Therapeutic peptide A delivery & Coated microneedles & $\begin{array}{l}\text { Naïve young adult } \\
\text { female Yucatan } \\
\text { minipigs }\end{array}$ & $\begin{array}{l}\text {-There was an efficient penetration of the } \\
\text { microneedles. } \\
\text {-The transfer from coated microneedles to } \\
\text { the skin was very efficient }\end{array}$ & $\begin{array}{l}\text { Kapoor Y. } \\
\text { et al., } \\
2019 \text { [65] }\end{array}$ \\
\hline
\end{tabular}


interact with actin filaments in the corneocytes, (c) allow partitioning augmentation and increase drug-protein solubility in the SC, and (d) improve penetration indirectly, modifying the drug (Fig. 3) [70]. Some of the most studied chemical penetration enhancers are the terpenes, amide, fatty acids, monoglycerides, and surfactants, and some of the most commonly studied are, D-limonene, azone, lauric acid, monoolein and sodium lauryl sulfate [71].

\section{Carriers}

In the drug delivery systems, some technologies are employed to permit the transport and delivery of certain molecules, such as peptides and proteins, decreasing the risk of degradation during their passage through the skin. These technologies allow and facilitate the transport, preservation, and delivery of these molecules. They are made from polymers, which are biocompatible and biodegradable and do not generate rejection or inflammatory reactions in the recipient. Some may be of natural origin and others of synthetic origin. Several methodologies have been developed to obtain specific morphologies of polymeric nanocarriers, such as nanofibers, nanospheres, nanoand microcapsules, polymersomes, polymeric micelles, and nanogels for medical applications $[72,73]$.

\section{Conveyors}

Depending on their chemical structure, some polymers can transport drug molecules within their structure, as in the case of cyclodextrins and their derivatives together with other saccharides (moieties) that can transport drugs as ketoprofen [74] or biomolecules such as levothyroxine sodium (T4) which has been used as a topical treatment to eliminate lipid deposits in subcutaneous adipose tissue. The main problem with this type of application has been the IT4 detection in rabbits $24 \mathrm{~h}$ after the application of the cream. The use of dimethyl-cyclodextrin as a solubilizer for levothyroxine increased its solubility, but unfortunately, it only succeeded in penetrating much less levothyroxine through the skin than the required dose in humans [75]. In this way, it is important to highlight that the complex improves the solubility of the molecule allowing it to pass through the SC, and in another specific treatment, it could recognize a specific target in the cell plasma membrane and then adhere to it and release its content in a more efficient way.

\section{Nano- and Microcarriers}

Nanocapsules Proteins are a substantial problem when we try to pass them through the skin. First, they are larger, and second, they are highly susceptible to enzymatic degradation. Not

Fig. 2 Main routes of protein drug administration

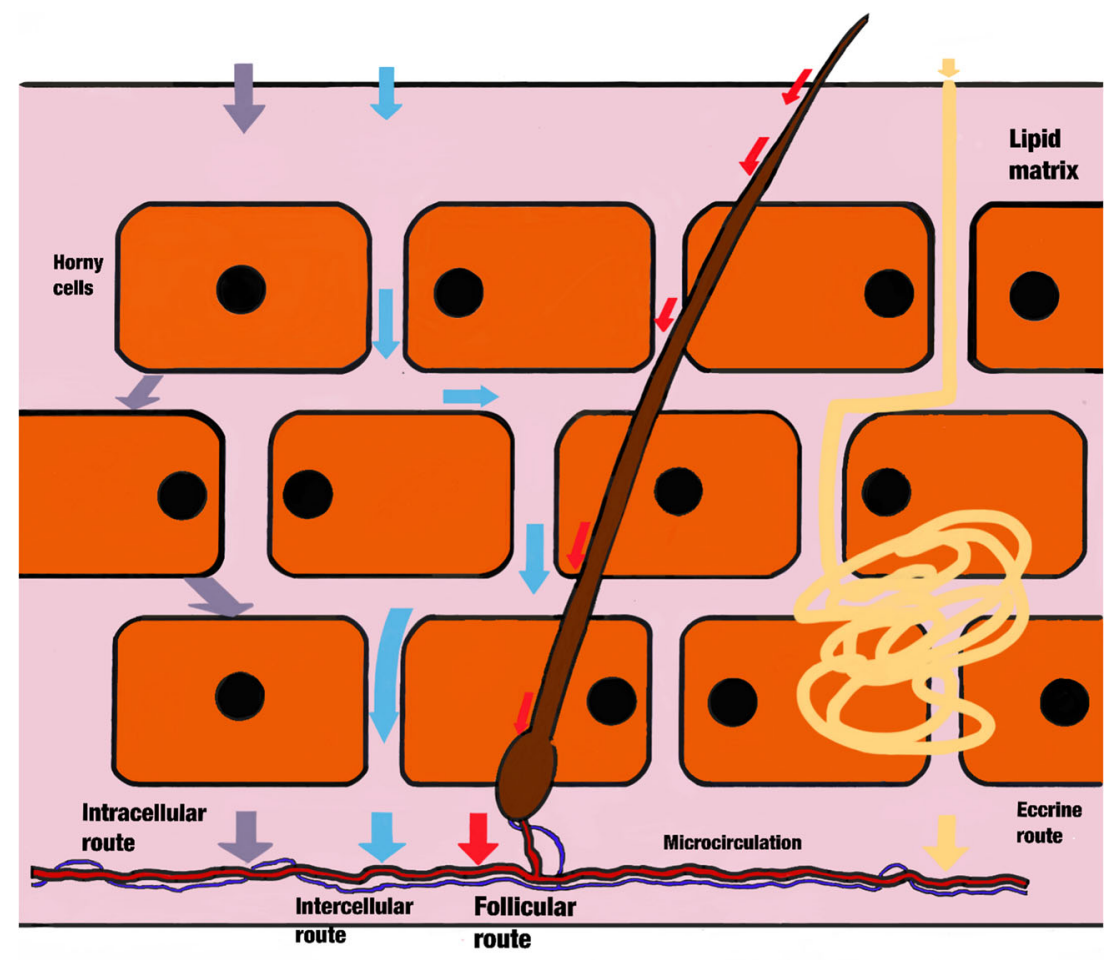


Fig. 3 Mechanisms of action of chemical penetration enhancers
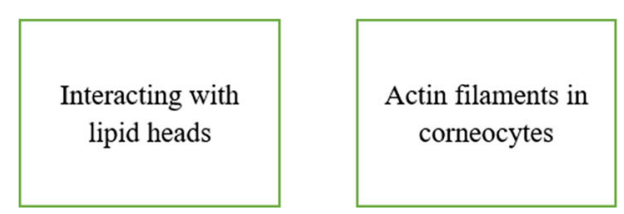

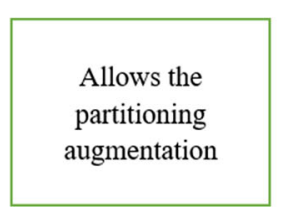

Improving

penetration all are thermostable, and finally, another difficulty is that proteins and peptides live for a short time in plasma. For this, it is necessary to protect them during their trip to the place of action. Furthermore, this protection enables controlled delivery. Passing through the skin can be less difficult if the protein is in a capsule, which is best when the capsule size is in the nanometric range.

Advances in the science of polymers applied in pharmacy have allowed the development of many encapsulation techniques that range from the most impractical to the most revolutionary methods. However, this reveals a problem, as some polymers are not soluble in water and require organic solvents. Furthermore, the integrity of the protein to be encapsulated is compromised regardless of the encapsulation technique.

Many types of polymers could be used in drug delivery; however, their chemical structure and molecular weight do not allow dissolution in water in many cases, and most dissolve well in organic solvents. The solubility of the polymer is a characteristic that is important to determine before use because it can determine the environmental resistance in the process in which it will be used.

Biopolymers and their combinations are best used for these procedures, helping to improve the stability of the formulation as in the case of encapsulating transforming growth factor (TGF- $\beta 1$ ) in poly(D,L-lactic-co-glycolic acid) (PLGA) and polyethylene glycol (PEG) polymeric microparticles for bone regeneration [76]. Insulin-loaded PCL-PEG-PCL NPs are another example where the NPs were prepared by the w/o/w double emulsion solvent evaporation method and demonstrated satisfactory insulin delivery and efficacy in treating diabetic rats [77]. These NPs possess a specific protein-drug delivery with a delivery degradation speed. They are hydrophobic or hydrophilic according to what is necessary for the encapsulation procedure and for improvement in the stability of the protein drug. They have a low or no chance of rejection and are safe to use.

Encapsulation processes are classified into two types (chemical and mechanical), which are then classified according to the methodology used to make the capsule. This can be determined according to the desired size, shape, and composition/surface chemistry. The encapsulation of biomolecules by these methods allows us to avoid the degradation of the free protein and allows the prolonged and constant release of a protein drug in constant time [78, 79].

With these methods, it is possible to obtain nano-sized particles, which are especially important to avoid their elimination by the immune system and the liver [80]. Smaller and softer particles can better evade the immune system, and this can be compatible with the recipient organism. It is important to note that capsules with a diameter size of $\leq 10 \mu \mathrm{m}$ have the risk of being engulfed by phagocytic immune cells; therefore, the recommended NP size that could have an appropriate delivery range is 10 to $200 \mathrm{~nm}$ [81].

Dendrimers Dendrimers are three-dimensional NPs, like macromolecules, and are considered based on nanometric size. These are radially symmetric and comprise an inner core structure made up of a central atom covalently bonded between other atoms. The external composition is highly branched, forming a dendrimer structure. These branches allow the formation of cavities into which bioactive molecules [82] can be incorporated, such as proteins [83] and peptides used for many pathological treatments [84] and for storage, transport, and controlled delivery.

There are many types of dendrimer structures, and depending on the synthesis method, these methods could use click chemistry [85] and divergent and convergent strategies. In addition, there are different designs and chemical elements. Their application in the administration of drugs has focused on the fact that these have many biocompatible characteristics. These characteristics include non-immunogenicity, non-toxicity, and a high ability to cross biological barriers, such as cell membranes, blood vessels, intestines, and the blood-brain barrier [86].

In addition, they have high stability in blood circulation and a prolonged blood circulation half-life, and they target specific structures. These NPs can be manufactured in high purity and have some degree of in vitro toxicity when manufactured with cationic and anionic surface groups. However, it is possible to reduce this toxicity by using surface protection by PEGs or fatty acids [87].

In TDD systems, dendrimers have been employed for the penetration of nonsteroidal anti-inflammatory drugs, such as indomethacin, which is an arthritis and osteoarthritis auxiliary drug in the treatment of the pain generated from this disease. There is a study that reports the progress of the TAT/PAMAM dendrimer system developed as a non-viral vector for the transdermal release of DNA plasmids where the dendrimer system was modified. The HIV transcriptional transactivator (TAT) was conjugated as a cell-penetrating peptide to enhance the uptake of constructed plasmid DNA pIRES-H5/GFP by cells [88]. Dendrimers are an excellent drug penetration enhancer [89] and they are some of the best nanostructures that 
have high applicability in medicine for the delivery of peptides and proteins.

\section{Microneedles}

When discussing NPs, it is appropriate to include another delivery system, MNs, which is a biomolecule delivery system that is like NPs in that it can store, transport, and deliver any molecule. Unlike NPs, MNs can contain nanometric dimensions in their internal structures and they can be as many as the length and thickness dimensions of the device can carry. These devices can have a small reservoir to store microliters or micrograms of protein drugs, alone or even encapsulated.

The MNs are a minimally invasive delivery method for the recipient and offer an excellent option for delivery systems in which the user must use a hypodermic metal needle to introduce the protein drug as in the case of insulin treatment [90]. The TDD insulin system in conjunction with MNs is a good delivery system that can avoid painful applications generated by constant hypodermic injections [91].

With MNs, devices are easier and less invasive drugprotein delivery systems. It is not necessary to employ other devices or an electric current supplement. The MNs can cross the SC, obtaining a local accumulation when the drug is being released into the bloodstream [92]. Moreover, these MN systems facilitate the passage of hydrophilic high-molecularweight molecules across the SC [93], such as proteins and peptides. The main role of MNs is to cross the SC. Therefore, they must have an appropriate structure that allows penetrating the $\mathrm{SC}$ and must retain it during the necessary time for protein-drug delivery. Many materials have been employed in MN manufacturing, such as metal (palladium, stainless steel, nickel, palladium-cobalt titanium [94]), ceramics [95], silicon [96], polymers [97], silica glass [98], and carbohydrates [99].

In addition, MNs have been used as a transport mechanism to cross the skin, and their design allows the passage of diverse sizes of molecules by employing the MN channels like a route for these molecules to enter and cross the skin, reaching the bloodstream more rapidly. The needles allow the storage and passage of molecules, and this capability is possible depending on the needle's morphology and chemical formulation.

For many protein drugs, this resource would be inadequate for transport and delivery because some biomolecules are too susceptible to enzymatic degradation. It is possible that, despite the use of MNs, they suffer partial or total degradation. With this disadvantage, it would be preferable to first encapsulate the biomolecule and then introduce it into the needles to be delivered into micro-conduits created by MNs that previously traveled through the SC, allowing free access to nanocapsules that contain the protein drug [100].

The MNs could have different characteristics that allow their application in some clinical treatments. The most important characteristic is the material that the MNs are manufactured with and their design, which depends on the necessities of the drug-protein delivery system. The delivery system can be hollow or solid [101-103], dissolving [97], degradable [104], and coated or uncoated [105]. Each has a specific function and exhibits very good results in the drug delivery system; however, some can allow proteins to pass across according to size. In many cases, it is possible to combine two or more polymers to generate MNs with a particular structure that allows better perforation of the skin that improves the passage of protein drug through the skin.

There are some proteins with regulatory activity as insulin, etanercept, growth hormone, erythropoietin, glucagon, glucagon-like peptide-1 (GLP-1), parathyroid hormone (PTH), desmopressin, and lysozyme which have been introduced into MNs for their transdermal delivery and the passage and delivery have been successful [106]. It has been observed that after the vaccine application by MNs there are an effective antigen presentation with the skin-resident dendritic cells. This effectivity has been compared with the traditional topical immunization where the result obtained by the MN immunization is the same as that of the intramuscular injection [107]. This TDD system with MNs is often used in the regulation of the immune system, for which monoclonal antibodies are used, mainly in cancer therapy, also known as immunotherapy. With the antibody, local administration is possible to avoid overstimulation of self-reactive $\mathrm{T}$ lymphocytes and then to avoid immune depletion [108].

\section{Transdermal Biomolecule Delivery Systems Focused on Using Nanoparticles into Microneedles}

As mentioned, traditional routes (intradermal, gastric, or intravenous) have long been the main delivery route for all drugs. Nevertheless, the appearance of an increase in chronic diseases has allowed the development of new technologies that are less invasive and have high efficiency upon reaching the target, especially in cases in which a user must take more than one medicine for the treatment of one or more diseases at a time.

Although the design and use of MNs can ensure the entrance of molecules across the skin, biomolecules have a high degradation risk that can occur at any time (in the charging process or at the moment of release). Thus, it is better to protect the protein contained within a specialized structure, such as nanocapsules or dendrimers (NPs in both cases). This procedure has no danger for the protein or peptide structural composition, which improves the conservation and passage of these compositions across the SC (Fig. 4).

The PLGA NPs can go through SC better with the help of MNs because the micro-conduits created by these needles allow the NPs to avoid the SC barrier and arrive at other skin layers and deliver the complete contents (Fig. 4) [109]. For 
Fig. 4 Schematic representation about the NP release from MNs into the epidermis

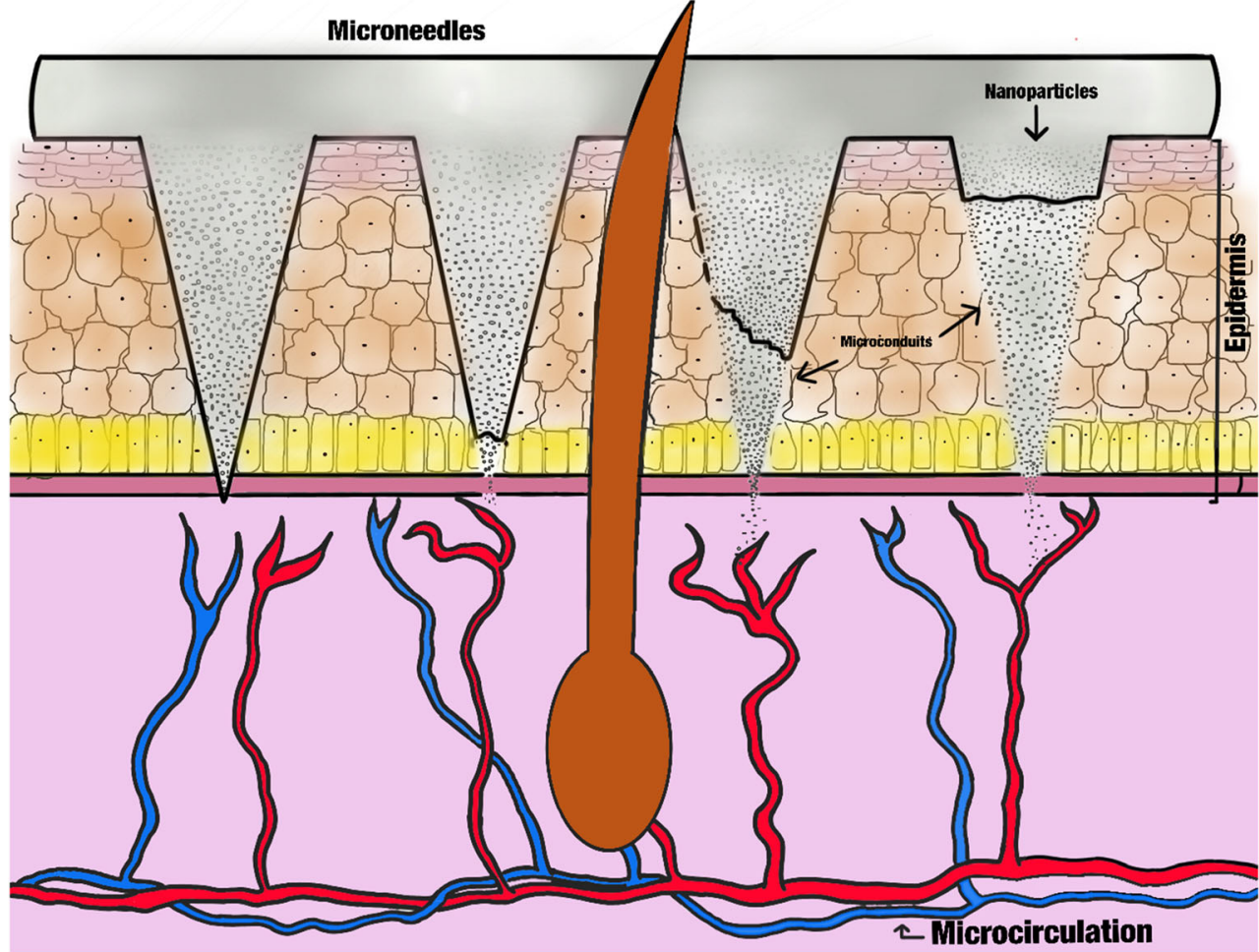

this procedure, it is necessary to consider that, in all cases, the penetration capacity of NPs depends on the particle and channel size [110]. Despite this important consideration, among others, the procedure also avoids the limitations of the skin's physicochemical properties that do not permit crossing it.

Some experimental studies have demonstrated the penetration and distribution of PLGA NPs in MNs [90]. The most common use of NPs/MNs is for experimental insulin release systems using murine models in rats with induced diabetes, where the insulin is introduced into $\mathrm{H}_{2} \mathrm{O}_{2}$-responsive mesoporous silica NPs, and MN patches are manufactured for later transdermal application. Its release behavior analysis demonstrated effective release [111]. For immunity induction, an excellent response occurs when the NPs/MNs were employed. For example, for the induction of immunity against endogenous prostate cancer stem cell antigen RALA/pPSCA, the immunization via the NP/MN release system resulted in anti-tumor activity in both cases of prophylactic and treatment assays in vivo [112]. Another experimental process that allows probing the system efficacy is the use of poly(methylmethacrylate) coated with $100 \mathrm{~nm}$ of gold NPs, which has great potential in tumoral cell destruction [27].

Currently, there are few authorized devices; however, these are increasing because for many treatments, such devices are more appropriately used, effective, and exhibit more recommended results. Perhaps shortly, these devices will be the most appropriate techniques for drug and protein delivery systems.

\section{Conclusions}

For many decades, a great number of therapies to resolve the problems associated with drug release have been implicated to probe numerous kinds of devices and pharmaceutical innovations to solve many diseases or applications in various clinical trials for the diagnosis of diseases or treatments of diseases. For this application, it is necessary to design new technologies, and pharmaceutical chemistry has been concerned with offering the best administration methods for therapeutic agents.

Lately, many research studies have reported numerous results that indicate the most appropriate technologies to use in each case of a drug delivery system. Each of the aforementioned TDD systems has some advantages and disadvantages for use in administering protein-drug delivery.

However, these technologies create substantial and important opportunities for administering biomolecules. In the coming years, we will observe an increase in their design, development, characterization, and clinical trials for the treatment of many important and chronic diseases.

Author Contributions All authors contributed to the study conception and design and to the material preparation, data collection, and analysis.

Funding Information This research was supported by PAPIIT CG 100220, PAPIME PE 201420, Cátedra PIAPI 2015, and CONACyT CF 140617. The first author wants to acknowledge the financial support from DGAPA-UNAM through a postdoctoral fellowship. 
Data Availability Not applicable.

\section{Compliance with Ethical Standards}

Conflict of Interest The authors declare no conflict of interest regarding the content and publication of this article.

Code Availability Not applicable.

Abbreviations SC, Stratum corneum; MNs, Microneedles; TPDD, Transdermal protein-drug delivery; TDD, Transdermal drug delivery; OP, Orthorhombic phase; LPP, Long-periodicity phase; FDA, Food and Drug Administration; NPs, Nanoparticles

\section{References}

1. Barbé C., Bartlett J., Kong L., Finnie K., Qiang Lin H., Larkin M., Calleja S., Bush and Calleja G. Silica particles: a novel drugdelivery system. Advanced Materials. 2004, 16, 21: 1959-1966.

2. Alkilani AZ, McCrudden MT, Donnelly RF. Transdermal drug delivery: innovative pharmaceutical developments based on disruption of the barrier properties of the stratum corneum. Pharmaceutics. 2015;7(4):438-70.

3. Prausnitz MR, Langer R. Transdermal drug delivery. Nat Biotechnol. 2008;26(11):1261-8.

4. Teo AL, Shearwood C, Ng KC, Lu J, Moochhala S. Transdermal microneedles for drug delivery applications. Mater Sci Eng B. 2006;132(1-2):151-4.

5. Scheuplein RJ. Mechanism of percutaneous absorption. II. Transient diffusion and the relative importance of various routes of skin penetration. J Investig Dermatol. 1967;48:79-88.

6. Wiechers, J. W. (1989). The barrier function of the skin in relation to percutaneous absorption of drugs. Pharmaceutisch Weekblad Scientific Edition 1989;11(6), 185-198.

7. Menon GK. New insights into skin structure: scratching the surface. Adv Drug Deliv Rev. 2002;54(Suppl 1):S3-S17.

8. Bolzinger M-A, Briançon S, Pelletier J, Chevalier Y. Penetration of drugs through skin, a complex rate-controlling membrane. Curr Opin Colloid Interface Sci. 2012;17(3):156-65.

9. Wiechers JW. The barrier function of the skin in relation to percutaneous absorption of drugs. Pharm Weekbl Sci. 1989;11(6):185-98.

10. Jensen, JM., and E. Proksch. The skin's barrier. Giornale Italiano di Dermatologia e Venereologia. 2009. 144. 689-700.

11. Vávrová K, Hrabálek A. Amino acid-based transdermal penetration enhancers. Percutaneous Penetration Enhancers Chemical Methods in Penetration Enhancement. 2015:325-36.

12. Williams AC, Barry BW. Penetration enhancers. Adv Drug Deliv Rev. 2004;56(5):603-18.

13. Escobar-Chavez, J., Diaz-Torres, R., Rodriguez-Cruz, I. M., Domínguez-Delgado, Sampere-Morales, Angeles-Anguiano, \& Melgoza-Contreras. Nanocarriers for transdermal drug delivery Research and Reports in Transdermal Drug Delivery 2012; (1) 3-17.

14. Prochazka AV. New developments in smoking cessation. Chest. 2000;117(4 Suppl 1):169S-75S.

15. Pailler-Mattei $\mathrm{C}, \mathrm{Bec} \mathrm{S}$, Zahouani $\mathrm{H}$. In vivo measurements of the elastic mechanical properties of human skin by indentation tests. Med Eng Phys. 2008;30(5):599-606.

16. Herwadkar A, Banga AK. Transdermal delivery of peptides and proteins. Peptide and Protein Delivery. 2011:69-86.

17. Alonso Castellanos S, Soto Célix M, Alonso Galarreta J, del Riego Valledor A, Miján de la Torre A. Efectos adversos metabólicos y nutricionales asociados a la terapia biológica del cáncer [Associated metabolic and nutritional side effects to biological cancer therapy]. Nutr Hosp 2014;29(2):259-268.
18. Ibraheem D, Elaissari A, Fessi H. Administration strategies for proteins and peptides. Int J Pharm. 2014;477(1-2):578-89.

19. Jin JF, Zhu LL, Chen M, Xu HM, Wang HF, Feng XQ, et al. The optimal choice of medication administration route regarding intravenous, intramuscular, and subcutaneous injection. Patient Prefer Adherence. 2015;2(9):923-42.

20. Zhiqiang Shen, Alessandro Fisher, Wing K. Liu, Ying Li. 1 PEGylated "stealth" nanoparticles and liposomes. In Woodhead Publishing Series in Biomaterials. Engineering of Biomaterials for Drug Delivery Systems. Woodhead Publishing. 2018.

21. Lee VHL, Yamamoto A. Penetration and enzymatic barriers to peptide and protein absorption. Adv Drug Deliv Rev. 1989;4(2): 171-207.

22. Torchilin VP, Lukyanov AN. Peptide and protein drug delivery to and into tumors: challenges and solutions. Drug Discov Today. 2003;8(6):259-66.

23. Wearley LL. Recent progress in protein and peptide delivery by noninvasive routes. Crit Rev Ther Drug Carrier Syst. 1991;8(4):331-94.

24. Zhou XH. Overcoming enzymatic and absorption barriers to nonparenterally administered protein and peptide drugs. J Control Release. 1994;29(3):239-52.

25. Dass CR, Choong PF. Biophysical delivery of peptides: applicability for cancer therapy. Peptides. 2006;27(12):3479-88.

26. Riley RS, June CH, Langer R, Mitchell MJ. Delivery technologies for cancer immunotherapy. Nat Rev Drug Discov. 2019 Mar;18(3):175-96.

27. Pachioni-Vasconcelos Jde A, Lopes AM, Apolinário AC, Valenzuela-Oses JK, Costa JS, Nascimento Lde O, et al. Nanostructures for protein drug delivery. Biomater Sci. 2016;4(2):205-18.

28. Siu KS, Chen D, Zheng X, Zhang X, Johnston N, Liu Y, et al. Non-covalently functionalized single-walled carbon nanotube for topical siRNA delivery into melanoma. Biomaterials. 2014;35(10):3435-42.

29. Pan J, Ruan W, Qin M, Long Y, Wan T, Yu K, et al. Intradermal delivery of STAT3 siRNA to treat melanoma via dissolving microneedles. Sci Rep. 2018;8(1):1117.

30. Li X, Xu Q, Zhang P, Zhao X, Wang Y. Cutaneous microenvironment responsive microneedle patch for rapid gene release to treat subdermal tumor. J Control Release. 2019;314:72-80.

31. Wang C, Ye Y, Hochu GM, Sadeghifar H, Gu Z. Enhanced cancer immunotherapy by microneedle patch-assisted delivery of antiPD1 antibody. Nano Lett. 2016;16(4):2334-40.

32. Ruan R, Chen M, Sun S, Wei P, Zou L, Liu J, et al. Topical and targeted delivery of siRNAs to melanoma cells using a fusion peptide carrier. Sci Rep. 2016;6:29159.

33. Niu J, Chu Y, Huang YF, Chong YS, Jiang ZH, Mao ZW, et al. Transdermal gene delivery by functional peptide-conjugated cationic gold nanoparticle reverses the progression and metastasis of cutaneous melanoma. ACS Appl Mater Interfaces. 2017;9(11):9388-401.

34. Ye Y, Wang J, Hu Q, Hochu GM, Xin H, Wang C, et al. Synergistic transcutaneous immunotherapy enhances antitumor immune responses through delivery of checkpoint inhibitors. ACS Nano. 2016;10(9):8956-63.

35. Wakabayashi R, Kono H, Kozaka S, Tahara Y, Kamiya N, Goto $\mathrm{M}$. Transcutaneous co-delivery of tumor antigen and resiquimod in solid-in-oil nanodispersions promotes anti-tumor immunity. ACS Biomaterials Science \& Engineering. 2019;5(5):2297-306.

36. Tran PHL, Duan W, Lee BJ, Tran TTD. Nanogels for skin cancer therapy via transdermal delivery: current designs. Curr Drug Metab. 2019;20(7):575-82.

37. Toyoda, M., Hama, S., Ikeda, Y., Nagasaki, Y., \& Kogure, K. Anti-cancer vaccination by transdermal delivery of antigen peptide-loaded nanogels via iontophoresis. International Journal of Pharmaceutics. 2015483(1-2), 110-114. 
38. Kim JH, Shin JU, Kim SH, Noh JY, Kim HR, Lee J, et al. Successful transdermal allergen delivery and allergen-specific immunotherapy using biodegradable microneedle patches. Biomaterials. 2018;150:38-48.

39. Jiang T, Xu G, Chen G, Zheng Y, He B, Gu Z. Progress in transdermal drug delivery systems for cancer therapy. Nano Res. 2020;13(7):1810-24.

40. Blattner CM, Coman G, Blickenstaff NR, Maibach HI. Percutaneous absorption of water in skin: a review. Rev Environ Health. 2014;29(3):175-80.

41. Elias PM. Epidermal lipids, barrier function, and desquamation. J Invest Dermatol. 1983;80(1 Suppl):44s-9s.

42. Barry BW. Drug delivery routes in skin: a novel approach. Adv Drug Deliv Rev. 2002;54(Suppl 1):S31-40.

43. Beddoes CM, Gooris GS, Bouwstra JA. Preferential arrangement of lipids in the long-periodicity phase of a stratum corneum matrix model. J Lipid Res. 2018;59(12):2329-38.

44. Madison KC. Barrier function of the skin: "la raison d'être" of the epidermis. J Invest Dermatol. 2003;121(2):231-41.

45. Escobar-Chávez JJ, Bonilla-Martínez D, Villegas-González MA, Revilla-Vázquez AL. Electroporation as an efficient physical enhancer for skin drug delivery. J Clin Pharmacol. 2009;49(11):1262-83.

46. Escobar-Chávez JJ, Merino V, López-Cervantes M, RodríguezCruz IM, Quintanar-Guerrero D, Ganem-Quintanar A. The use of iontophoresis in the administration of nicotine and new nonnicotine drugs through the skin for smoking cessation. Curr Drug Discov Technol. 2009;6(3):171-85.

47. Karpiński TM. Selected medicines used in iontophoresis. Pharmaceutics. 2018;10(4):204.

48. Guy RH. Iontophoresis-recent developments. J Pharm Pharmacol. 1998;50(4):371-4.

49. Prausnitz MR. A practical assessment of transdermal drug delivery by skin electroporation. Adv Drug Deliv Rev. 1999;35:61-76.

50. Ita K. Recent progress in transdermal sonophoresis. Pharm Dev Technol. 2017;22(4):458-66.

51. Escobar-Chávez JJ, Bonilla-Martínez D, Villegas-González MA, Rodríguez-Cruz IM, Domínguez-Delgado CL. The use of sonophoresis in the administration of drugs throughout the skin. J Pharm Pharm Sci. 2009;12(1):88-115.

52. Donnelly RF., Singh TRR., Morrow DIJ., Woolfson AD. Microneedle-mediated transdermal and intradermal drug delivery. 1st. Edition. 9600 Garsington Road, Oxford, OX4 2DQ, UK: Wiley-BlackWell; 2012.

53. Kumar R, Philip A. Modified transdermal technologies: breaking the barriers of drug permeation via the skin. Trop J Pharm Res. 2007;6:633-44.

54. Donnelly RF., Singh TRR., Morrow DIJ., Woolfson AD. Microneedle-mediated transdermal and intradermal drug delivery. 1st. Edition. 9600 Garsington Road, Oxford, OX4 2DQ, UK: Wiley-BlackWell; 2012; 1-19.

55. Xie X, Xu AM, Leal-Ortiz S, Cao Y, Garner CC, Melosh NA. Nanostraw-electroporation system for highly efficient intracellular delivery and transfection. ACS Nano. 2013;7(5):4351-8. https://doi.org/10.1021/nn400874a.

56. Ma L, Jang L, Chen J, Song J, Yang D, Zhang J, Chen YE, Xu J. CRISPR/Cas9 ribonucleoprotein-mediated precise gene editing by tube electroporation. J Vis Exp. 2019; 20;(148). doi: https:// doi.org/10.3791/59512.

57. Wiegert, J. S., Gee, C. E., \& Oertner, T. G. (2017). Single-cell electroporation of neurons. Cold Spring Harbor Protocols, 2017(2), pdb. prot094904. doi:10.1101/pdb. prot094904.

58. Xie X, Muruato A, Lokugamage KG, Narayanan $\mathrm{K}$, Zhang X, Zou J, Liu J, Schindewolf C, Bopp NE, Aguilar PV, Plante KS, Weaver SC, Makino S, LeDuc JW, Menachery VD, Shi PY. An infectious cDNA clone of SARS-CoV-2. Cell Host Microbe.
2020; 13;27(5):841-848.e3. doi: https://doi.org/10.1016/j.chom. 2020.04.004.

59. Bai Y, Sachdeva V, Kim H, Friden PM, Banga AK. Transdermal delivery of proteins using a combination of iontophoresis and microporation. Ther Deliv. 2014;5(5):525-36. https://doi.org/10. 4155/tde.14.19.

60. Tian AP, Yin YK, Yu L, Yang BY, Li N, Li JY, et al. Low-frequency sonophoresis of Chinese medicine formula improves efficacy of malignant pleural effusion treatment. Chin J Integr Med. 2020;26(4): 263-9. https://doi.org/10.1007/s11655-019-3167-7.

61. Hur GH, Han SC, Ryu AR, Eom Y, Kim JW, Lee MY. Effect of oligoarginine conjugation on the antiwrinkle activity and transdermal delivery of GHK peptide. J Pept Sci. 2020;26(2):e3234. https://doi.org/10.1002/psc.3234.

62. Liu D, Yu B, Jiang G, Yu W, Zhang Y, Xu B. Fabrication of composite microneedles integrated with insulin-loaded $\mathrm{CaCO}_{3}$ microparticles and PVP for transdermal delivery in diabetic rats. Mater Sci Eng C Mater Biol Appl. 2018;1(90):180-8. https://doi. org/10.1016/j.msec.2018.04.055.

63. Gan BK, Yong CY, Ho KL, Omar AR, Alitheen NB, Tan WS. Targeted delivery of cell penetrating peptide virus-like nanoparticles to skin cancer cells. Sci Rep. 2018; 31;8(1):8499. doi: https:// doi.org/10.1038/s41598-018-26749-y.

64. Manikkath J, Hegde AR, Kalthur G, Parekh HS, Mutalik S. Influence of peptide dendrimers and sonophoresis on the transdermal delivery of ketoprofen. Int J Pharm. 2017; 15;521(1-2):110 119. doi: https://doi.org/10.1016/j.ijpharm.2017.02.002.

65. Kapoor Y, Milewski M, Dick L, Zhang J, Bothe JR, Gehrt M, Manser K, Nissley B, Petrescu I, Johnson P, Burton S, Moseman J, Hua V, Grunewald T, Tomai M, Smith R. Coated microneedles for transdermal delivery of a potent pharmaceutical peptide. Biomed Microdevices. 2019; 16;22(1):7. doi: https://doi.org/10. 1007/s10544-019-0462-1.

66. Lee JN, Jee SH, Chan CC, Lo W, Dong CY, Lin SJ. The effects of depilatory agents as penetration enhancers on human stratum corneum structures. J Invest Dermatol. 2008;128(9):2240-7.

67. Lee H, Song C, Baik S, Kim D, Hyeon T, Kim DH. Deviceassisted transdermal drug delivery. Adv Drug Deliv Rev. 2018;127:35-45.

68. Barry BW. Lipid-protein-partitioning theory of skin penetration enhancement. J Control Release. 1991;15(3):237-48.

69. Dragicevic N, Atkinson JP, Maibach HI. Chemical penetration enhancers: classification and mode of action. Percutaneous Penetration Enhancers Chemical Methods in Penetration Enhancement. 2015:11-27.

70. García MC., Aloisio C., Onnainty R., Ullio-Gamboa G. Selfassembled nanomaterials. In: Narayan R, editor. Nanobiomaterials: nanostructured materials for biomedical applications. $1^{\text {st }}$ ed: Cambridge, UK: Woodhead Publishing; 2017.

71. Lopes, L. B., J Garcia, M. T., \& LB Bentley, M. V. Chemical penetration enhancers. Ther Deliv 2015; 6(9), 1053-1061.

72. Tang Z, He C, Tian H, DIng J, Hsiao BS, Chu B, et al. Polymeric nanostructured materials for biomedical applications. Progress Polymer Sci. 2016;60:86-128.

73. Oda Y, Kobayashi N, Yamanoi T, Katsuraya K, Takahashi K, Hattori K. Beta-cyclodextrin conjugates with glucose moieties designed as drug carriers: their syntheses, evaluations using concanavalin A and doxorubicin, and structural analyses by NMR spectroscopy. Med Chem. 2008;4(3):244-55.

74. Sridevi S, Diwan PVR. Optimized transdermal delivery of ketoprofen using $\mathrm{pH}$ and hydroxypropyl- $\beta$-cyclodextrin as co-enhancers. Eur J Pharm Biopharm. 2002;54(2):151-4.

75. Padula C, Pappani A, Santi P. In vitro permeation of levothyroxine across the skin. Int J Pharm. 2008;349(1-2):161-5. 
76. Lu L, Stamatas GN, Mikos AG. Controlled release of transforming growth factor beta1 from biodegradable polymer microparticles. J Biomed Mater Res. 2000;50(3):440-51.

77. Patel A, Patel M, Yang X, Mitra AK. Recent advances in protein and peptide drug delivery: a special emphasis on polymeric nanoparticles. Protein Pept Lett. 2014;21(11):1102-20.

78. Yeo Y, Baek N, Park K. Microencapsulation methods for delivery of protein drugs. Biotechnol Bioprocess Eng. 2001;6(4):213-30.

79. Ma G. Microencapsulation of protein drugs for drug delivery: strategy, preparation, and applications. J Control Release. 2014;193:324-40.

80. Najafi-Hajivar S, Zakeri-Milani P, Mohammadi H, Niazi M, Soleymani-Goloujeh M, Baradaran B, et al. Overview on experimental models of interactions between nanoparticles and the immune system. Biomed Pharmacother. 2016;83:1365-78.

81. Han FY, Thurecht KJ, Whittaker AK, Smith MT. Bioerodable PLGA-based microparticles for producing sustained-release drug formulations and strategies for improving drug loading. Front Pharmacol. 2016;7:185.

82. Sandoval-Yañez C, Castro RC. Dendrimers: amazing platforms for bioactive molecule delivery systems. Materials (Basel). 2020;13(3):570.

83. Dąbkowska M, Rogińska D, Kłos P, Sobuś A, Adamczak M, Litwińska Z, et al. Electrostatic complex of neurotrophin 4 with dendrimer nanoparticles: controlled release of protein in vitro and in vivo. Int J Nanomedicine. 2019;14:6117-31.

84. Dong Y, Yu T, Ding L, Laurini E, Huang Y, Zhang M, et al. A dual targeting dendrimer-mediated siRNA delivery system for effective gene silencing in cancer therapy. J Am Chem Soc. 2018;140(47):16264-74.

85. Anandkumar D, Rajakumar P. Synthesis and anticancer activity of bile acid dendrimers with triazole as bridging unit through click chemistry. Steroids. 2017;125:37-46.

86. Zhu Y, Liu C, Pang Z. Dendrimer-based drug delivery systems for brain targeting. Biomolecules. 2019;9(12):790.

87. Boas U, Heegaard PM. Dendrimers in drug research. Chem Soc Rev. 2004;33(1):43-63.

88. Bahadoran A, Moeini H, Bejo MH, Hussein MZ, Omar AR. Development of Tat-conjugated dendrimer for transdermal DNA vaccine delivery. J Pharm Pharm Sci. 2016 Jul-Sep;19(3):325338. doi: https://doi.org/10.18433/J3G31Q.

89. Chauhan AS, Sridevi S, Chalasani KB, Jain AK, Jain SK, Jain N, et al. Dendrimer-mediated transdermal delivery: enhanced bioavailability of indomethacin. J Control Release. 2003;90(3):335-43.

90. Xu B, Jiang G, Yu W, Liu D, Zhang Y, Zhou J, et al. $\mathrm{H}_{2} \mathrm{O}_{2^{-}}$ responsive mesoporous silica nanoparticles integrated with microneedle patches for the glucose-monitored transdermal delivery of insulin. J Mater Chem B. 2017;5(41):8200-8.

91. Mo R, Jiang T, Di J, Tai W, Gu Z. Emerging micro- and nanotechnology based synthetic approaches for insulin delivery. Chem Soc Rev. 2014;43(10):3595-629.

92. Rzhevskiy AS, Singh TRR, Donnelly RF, Anissimov YG. Microneedles as the technique of drug delivery enhancement in diverse organs and tissues. J Control Release. 2018;270:184-202.

93. Waghule T, Singhvi G, Dubey SK, Pandey MM, Gupta G, Singh M, et al. Microneedles: a smart approach and increasing potential for transdermal drug delivery system. Biomed Pharmacother. 2019;109:1249-58.

94. Donnelly RF, Raj Singh TR, Woolfson AD. Microneedle-based drug delivery systems: microfabrication, drug delivery, and safety. Drug Deliv. 2010;17(4):187-207.
95. Ita K. Ceramic microneedles and hollow microneedles for transdermal drug delivery: two decades of research. Journal of Drug Delivery Science and Technology. 2018;44:314-22.

96. Sharma D; Microneedles: an approach in transdermal drug delivery: a Review; PharmaTutor; 2018; 6(1); 7-15;).

97. Ye Y, Yu J, Wen D, Kahkoska AR, Gu Z. Polymeric microneedles for transdermal protein delivery. Adv Drug Deliv Rev. 2018;127:106-18.

98. Larrañeta, E., Lutton, R. E. M., Woolfson, A. D., \& Donnelly, R. F. (2016). Microneedle arrays as transdermal and intradermal drug delivery systems: materials science, manufacture and commercial development. Materials Science and Engineering: R: Reports 2016;104, 1-32.

99. Miyano T, Tobinaga Y, Kanno T, Matsuzaki Y, Takeda H, Wakui $\mathrm{M}$, et al. Sugar micro needles as transdermic drug delivery system. Biomed Microdevices. 2005;7(3):185-8.

100. Lim DJ, Vines JB, Park H, Lee SH. Microneedles: a versatile strategy for transdermal delivery of biological molecules. Int $\mathrm{J}$ Biol Macromol. 2018;110:30-8.

101. Prausnitz MR. Microneedles for transdermal drug delivery. Adv Drug Deliv Rev. 2004;56(5):581-7.

102. Serrano Castañeda P, Escobar-Chávez JJ, Arroyo Vázquez J, Marlen I, Cruz R, María L, et al. Pravastatin transdermal patch: effect of the formulation and length of microneedles on in-vitro percutaneous absorption studies. Iran J Pharm Res. 2020;19(2):9-15.

103. Anguiano-Almazan E, Serrano-Castañeda P, Díaz-Torres R, Escobar-Chavez JJ. Design and evaluation of losartan transdermal patch by using solid microneedles as a physical permeation enhancer. Iran J Pharm Res. 2020;19(1):138-52.

104. Pineda-Álvarez RA, Bernad-Bernad MJ, Rodríguez-Cruz IM, Escobar Chávez JJ. Development and characterization of starch/ gelatin microneedle arrays loaded with lecithin-gelatin nanoparticles of losartan for transdermal delivery. J Pharmaceut Innov. 2020. https://doi.org/10.1007/s12247-020-09494-6.

105. Bhatnagar S, Dave K, Venuganti VVK. Microneedles in the clinic. J Control Release. 2017;260:164-82.

106. Ye Y, Yu J, Wen D, Kahkoska AR, Gu Z. Polymeric microneedles for transdermal protein delivery. Adv Drug Deliv Rev 2018; 1; 127:106-118.

107. Glenn GM, Taylor DN, Li X, Frankel S, Montemarano A, Alving CR. Transcutaneous immunization: a human vaccine delivery strategy using a patch. Nat Med. 2000;6(12):1403-6.

108. Li G, Badkar A, Nema S, Kolli CS, Banga AK. In vitro transdermal delivery of therapeutic antibodies using maltose microneedles. Int J Pharm. 2009;368:109-15.

109. Zhang W, Gao J, Zhu Q, Zhang M, Ding X, Wang X, et al. Penetration and distribution of PLGA nanoparticles in the human skin treated with microneedles. Int J Pharm. 2010;402(1-2):205-12.

110. Coulman SA, Anstey A, Gateley C, Morrissey A, McLoughlin P, Allender C, et al. Microneedle mediated delivery of nanoparticles into human skin. Int J Pharm. 2009;366:190-200.

111. Cole G, Ali AA, McErlean E, Mulholland EJ, Short A, McCrudden CM, et al. DNA vaccination via RALA nanoparticles in a microneedle delivery system induces a potent immune response against the endogenous prostate cancer stem cell antigen. Acta Biomater. 2019;96:480-90.

112. Moothanchery M, Seeni RZ, Xu C, Pramanik M. In vivo studies of transdermal nanoparticle delivery with microneedles using photoacoustic microscopy. Biomed Opt Express. 2017;8:5483-92.

Publisher's Note Springer Nature remains neutral with regard to jurisdictional claims in published maps and institutional affiliations. 